\title{
Father departure and children's mental health: how does timing matter?
}

\author{
Emla Fitzsimons ${ }^{1,2}$ \\ Aase Villadsen ${ }^{1}$
}

\begin{abstract}
Father's permanent departure from the household in childhood has the potential to affect child mental health. The event is non-random, and a major limitation in most previous studies is lack of adequate control for unobserved confounders. Using five waves of data spanning ages 3 to 14 from the Millennium Cohort Study, a UK-wide nationally representative longitudinal study, this paper uses fixed effect models to examine the effect of paternal absence on children's mental health (i.e. externalising and internalising problems) in a sample of 6,245 children. Heterogeneity of effects are examined by gender and maternal education. A novel aspect is to examine how the timing of departure matters, and to assess whether there are developmental periods that are especially sensitive to paternal departure, and whether effects are temporary or enduring. We find that paternal departure has a negative effect on child mental health, particularly on internalising symptoms. Striking gender differences emerge in examining effects by timing and duration. There are no short-term effects of departure in early childhood, and only weak evidence of females showing an increase in internalising symptoms in the medium-term. Paternal departure in later childhood, on the other hand, is associated with an increase in internalising problems in both males and females, and increased externalising symptoms for males only. We do not find maternal education to be a protective factor.
\end{abstract}

Keywords: Father departure; Child externalising; Child internalising; Millennium Cohort Study; Fixed effects

Corresponding author:

Aase Villadsen

UCL Institute of Education

Centre for Longitudinal Studies

55-59 Gordon Square

WC1 $0 \mathrm{NU}$

London

a.villadsen@ucl.ac.uk

${ }^{1}$ UCL Institute of Education, London

${ }^{2}$ Institute for Fiscal Studies, London 


\section{Introduction}

Childhood adversity, including stressful life events, strongly determines long-term mental health problems (Shonkoff et al. 2012). A particularly significant event is the father's permanent departure from the household. The implications for children's mental wellbeing are complex and theoretically ambiguous. On the one hand, the shift in living arrangements and frequency of paternal contact may adversely affect the child, and reductions in household income may also be welfare-reducing; on the other hand, the dissolution of emotionally or physically harmful partnerships can be beneficial for children (Emery 1999). The effects further depend on several factors including changes in mental health functioning, quality of parenting and ability to maintain a positive parent-child relationship (Amato 2010, Whiteside and Becker 2000). Moreover, life course theory postulates that effects may vary depending on timing of exposure (Ben-Shlomo and Kuh 2002, Kuh et al. 2003). However, little evidence exists on the extent to which timing of exposure to paternal departure matters in shaping children's mental health.

This paper estimates the effect of paternal departure from the household on children's mental health from early childhood through mid-adolescence. Paternal departure refers to the father moving out of the family home permanently due to relationship dissolution (divorce or separation). It is the most common shift in living arrangements following relationship dissolution; for instance in the UK, mothers account for $90 \%$ of lone parents with dependent children (Office for National Statistics, 2016). Its effects are estimated using fixed effects models on rich longitudinal data, the UK Millennium Cohort Study, which follows individuals from birth. It distinguishes between departures at different stages of childhood - "early childhood" (before age 7) and "mid-childhood" (between ages 7 and 14) - and estimates the short- and medium-run effects on children's mental health, in line with the critical period 
model of life course theory (Ben-Shlomo and Kuh 2002; Kuh et al. 2003). It studies effects to mid-adolescence (age 14), including how they vary by gender and maternal education. It considers separately internalising and externalising symptoms of mental health.

The majority of evidence to date, summarised in section 2, comes from the US, and our paper fills an important niche in providing evidence for the UK, using a nationally representative contemporaneous sample of children. An additional contribution is in distinguishing between departures occurring in early and middle childhood, and employing robust empirical methods to estimate the effects on children's mental health in the short- and medium-run. This adds to the limited body of evidence on this matter, and is the first UK study to do this.

The paper proceeds as follows. Section 2 summarises the literature, and is followed by a description of the data in section 3 , the empirical methodology in section 4 , and results in section 5. Section 6 provides a discussion of findings.

\section{Related Literature}

An extensive literature documents detrimental effects of family breakdown on a range of child and adolescent outcomes, including conduct and emotional problems (Green et al. 2005). The meta-analysis of Amato and Keith (1991) on early studies on divorce reported average standardised effect sizes of 0.23 for conduct problems and 0.08 for emotional problems. In a more recent meta-analysis, larger effect sizes were found, of around 0.30 for conduct and emotional problems (Amato 2001). However, a limitation of these studies concerns the nonrandom nature of paternal departure (instance.g. Van de Walle 2011). For instance, couples may separate because they have different preferences for investment in children, rendering it 
important to untangle effects of separation from effects of unmeasured preferences, in order to estimate its causal effect on outcomes. Whilst most studies control for several confounding factors, one cannot rule out the presence of unobserved factors influencing both family dissolution and children's outcomes.

Previous work has used quasi-experimental methods to overcome this problem, for instance, changes in divorce laws (Gruber 2004), differing child sex composition (Dahl and Moretti 2008), within-family estimation (Markowitz and Ryan 2016), and children of sibling designs (D'Onofrio et al. 2005, D'Onofrio et al. 2006). In a review of studies using methods focused on causal identification, McLanahan et al. (2013) conclude that parental separation has a negative effect on children's developmental outcomes, including mental health, but the magnitude of the effects is smaller than in cross-section designs.

An additional important question is whether there are particularly sensitive periods during which children are more adversely affected by paternal departure. It is plausible that the effects vary depending on when in childhood they occur (Cavanagh and Huston, 2008). On the one hand, attachment theory highlights the importance of early childhood for children's social development, with family disruptions and stress having negative effects on those parent-child relationships that allow children to develop and maintain healthy social relationships (Bowlby 1969). On the other hand, social cognitive theory suggests that middle childhood is a critical time when children have a better cognitive capacity to understand relationship dynamics (Bandura 1986). Family instability during this period can affect their relationship skills and social competence. Children may model negative behaviours that are less conducive to forming and maintaining friendships (Collins and Laursen 1992; Doyle and Markiewicz 1996). Life course theory also provides a strong theoretical underpinning. In particular, the 
critical/sensitive period model postulates that an exposure in a particular window of time results in long-term developmental changes (Ben-Shlomo and Kuh 2002, Kuh et al. 2003). Whilst traditionally considered distinct from the accumulation model of life course theory, in which exposures accumulate throughout life and may cause long-term damage, recent thinking suggests that the sensitive period model is a special sub-set of it (Ben-Shlomo et al. 2014).

There is scant evidence on the effects of the timing of family disruption, and the few studies that exist are mainly US-based. Cherlin et al. (1991) estimate the association between divorce in mid childhood (7-11) and outcomes in adolescence, concluding that much of the effect of divorce is likely driven by unobserved characteristics of children and households present before divorce. Cavanagh and Huston (2008) study this using the NICHD Study of Early Child Care and Youth Development, finding a lasting effect of family change in early childhood, particularly for boys. To our knowledge, only a handful of studies examine the temporal effects of the disruption process while addressing the problem of unobserved differences, all of them using the National Longitudinal Survey of Youth. Results point towards father's departure in early childhood (first five years) having more of an adverse impact on children's development than departure later in childhood (Ryan et al. 2015, Ryan \& Claessens 2013). Aughinbaugh et al. (2005) find little evidence of any temporal effect on cognitive and non-cognitive outcomes, though the narrow time periods they consider is a limitation.

A related question concerns the longevity of any impact, and whether any short-run effects fade out, persist or become accentuated over time. Whilst Amato and Keith (1991) find that the effects of divorce become attenuated over time, the caveat is that this is based on methods that do not adequately account for the endogeneity of paternal departure. Similarly, Cherlin et al. (1998) find associations between parental divorce and adult mental health, but cannot rule out 
that it may be due to unmeasured confounding. Lansford et al. (2006) find that early parental separation is more negatively related to trajectories of internalising and externalising problems than is later separation, whereas later separation is more negatively related to grades. We are aware of just two studies that examine temporal effects of divorce on children's mental health outcomes, using methods to deal with the endogeneity of divorce. Arkes et al. (2015) find evidence of fade-out in the effects on children's behavioural problems over time; Pronzato and Aassve (2013) find that children's peer problems and hyperactivity are affected in the shortterm only, whilst emotional problems are affected in both the short- and long- term.

We bring both strands of this literature together, in assessing both how timing of the event matters, and whether the effects persist, fade out or become accentuated over time.

Our study also considers heterogeneity along two key dimensions: sex and maternal education. Regarding sex, there is evidence that males are more susceptible to the stress and uncertainty associated with family instability (Capaldi and Patterson 1991, Cavanagh et al. 2008, Cavanagh and Huston 2008). Previous studies on this show mixed results (Amato, 2010), although most do not account for the endogeneity of the father's departure from the household. One exception is Markowitz and Ryan (2016), who find no gender differences in the links between father absence and adolescent behaviour. In a related study focused on the effect of living in a family structure other than with two biological parents and full siblings, using sibling fixed effects, it was found that males see increases in both externalising and internalising problems, whilst internalising problems increase for females (Mostafa, Gambaro and Joshi 2018).

The second dimension of heterogeneity assessed is maternal education. Because the mother becomes the main caregiver following parental separation in the vast majority of cases 
(upwards of $90 \%$ in our sample), maternal education is hypothesised to exert the more significant impact on children's outcomes. Economic theory suggests that families with more economic and educational resources may be better able to withstand detrimental effects of the event because of higher economic and personal resources, and that less advantaged families are more susceptible to income shocks. For instance, Mandemakers and Kalmijn (2014) find that children of more highly educated mothers are less adversely affected by divorce in terms of their psychological wellbeing; Weaver and Schofield (2015) find that children from high income families are less affected by behavioural problems following separation. Life course theory, on the other hand, suggests that children from more disadvantaged backgrounds are likely to be less affected due to a less pronounced income effect, and it being a more normative event. The study of Ryan et al. (2015) finds evidence to support this.

Finally, we consider potential mechanisms and the extent to which maternal mental health and household income are affected by the event and may be underlying findings. For instance, Brewer and Nandi (2014) find evidence that women and children see living standards decline by more than men, on average, upon separation, and the fall in living standards is greater for women and children in high-income households; they also find that mental health and life satisfaction decline around separation, but both return quickly to pre-split levels. Similarly, Blekesaune (2008) finds an increase in mental distress following partnership dissolution, but individuals tend to recover and the effect is small.

\section{Data}

\subsection{Source}

We use data from the UK Millennium Cohort Study (MCS), a major ongoing longitudinal study following a cohort of over 19,000 children in the UK born between 2000 and 2002 (Joshi and 
Fitzsimons 2016). 19,244 families were recruited at baseline, representing an overall response rate of $71 \%$. Families were first assessed when children were 9 months old, and followed up at ages $3,5,7,11$ and $14.61 \%$ of the initial respondents were in the study at the sixth wave. Weights are used to adjust for inter-wave attrition (Fitzsimons 2017).

In each wave, an interview is carried out with the main parent (normally the mother), resident partners, and, at ages 7, 11 and 14, the cohort member. Each wave contains information on the family, including: parental education; employment and income; housing; family structure; ethnicity; parenting activities such as reading to child; developmental indicators; parental relationship status; and parental mental health. Child cognitive development is measured directly from age 3 onwards. Child mental health is measured at the same ages via parental report, described below.

\subsection{Sample Selection}

Children's externalising and internalising behaviour was first measured at wave 2 (age 3) and has been measured at each wave since. We therefore select families who participated in wave 2 , and restrict the sample to those living with both biological parents, in order to estimate the effect of subsequent departure. A small number of families where parents separated multiple times and where the father died are excluded, and we restrict the sample to those where mothers are the main respondent (the majority $-96 \%$ ). Families with twins and triplets are excluded, so the focus is on singleton children, to retain a homogeneous sample. Finally, we retain those with valid responses on the child externalising and internalising measure at all waves. The final study sample contains 6,245 children, across five waves, as shown in Table S1 of supplementary material. 


\subsection{Measures}

\section{Child Mental Health}

The widely used Strengths and Difficulties Questionnaire (SDQ; Goodman 1997) was administered to mothers to assess children's mental health. It has been validated as a useful, dimensional measure of child mental health (Goodman and Goodman 2009; Mathai et al. 2004). The instrument contains 25 items relating to the child's behaviour, covering five scales: emotional symptoms, conduct problems, hyperactivity/inattention, peer relationship problems, and prosocial behaviour. Ratings on each item are: not true (0), somewhat true (1), or certainly true (2). We use as outcomes the two amalgamated scales, shown to perform better than the five separate subscales in low-risk general population samples (Goodman et al. 2010): child externalising (conduct problems and hyperactivity) and child internalising (emotional symptoms and peer problems). The prosocial scale is not included as the absence of prosocial behaviours is conceptually distinct from the presence of psychological difficulties (Goodman 1997). Both measures are scored from 0 to 20, with higher scores signifying higher levels of externalising and internalising symptoms. In our sample the internal consistency of the items making up the scales, across child ages $3,5,7,11$ and 14 , ranges from $\alpha=0.76$ (age 3 ) to $\alpha=0.79$ (age 14) for externalising, and from $\alpha=0.59$ (age 3) to $\alpha=0.77$ (age 14) for internalising.

\section{Paternal Departure}

Permanent departure of the child's biological father from the household is measured from age 3 onwards. Information on who lived in the household and their relationship to other members in the household was provided by the main respondent at each wave. To measure paternal departure, we combine information on the marital/ partnership status of the mother at times $\mathrm{t}-$ 1 and $t$, and the status of the father at time $t$. In particular, if the mother's reported status at time 
$\mathrm{t}-1$ is married/cohabiting with father, and at time $\mathrm{t}$ is no longer living with the child's father, and if the father's status at time $\mathrm{t}$ is no longer in the household, we consider this a permanent departure of the father. In our analytic sample, $19 \%$ experienced paternal departure during the period corresponding to cohort child age 3-14.

\section{Control Variables}

OLS models control for baseline measures (wave 2): maternal education, maternal ethnicity, and social class based on the UK National Statistics Socio-economic Classification system (NS-SEC) with 13 categories. Additional control variables are maternal age at birth, child gender, quadratic in child age, country dummies, and dummies for study wave.

\section{Methods}

We estimate child fixed effect models to address the endogeneity of paternal departure. As there is just one child sampled per household (the 'cohort member'), this is analogous to household fixed effects. The estimating equation is

$$
y_{i t}=\beta_{0}+\beta_{1} D_{i t}+X_{i t}^{\prime} \beta_{2}+f_{i}+\delta_{t}+u_{i t}
$$

where $\mathrm{i}$ denotes the child; $\mathrm{t}$ denotes time $(\mathrm{t}=1$ denotes age $3 /$ wave $2 \ldots t=5$ denotes age $14 /$ wave 6); $y_{i t}$ is internalising/externalising behaviour; and $D_{i t}$ is an indicator taking the value one if child $\mathrm{i}$ has experienced paternal departure by time $\mathrm{t}$ and zero otherwise. Note that, by definition, $D_{i 1}=0$ (as it is departure that occurred by time $t$; but we restrict to intact families at time $t=1$ ). So for instance, if departure occurred between ages 3 and 5 , then $D_{i 1}=D_{i 2}=D_{i 3}=D_{i 4}=D_{i 5}=1$; if it occurred between ages 5 and 7 , then $D_{i 1}=0, D_{i 2}=D_{i 3}=D_{i 4}=D_{i 5}=1 . X_{i t}$ is a vector of time-varying 
child age and quadratic age; $\mathrm{f}_{\mathrm{i}}$ is a child fixed effect capturing unobserved time-invariant child and household characteristics; $\delta_{\mathrm{t}}$ is a survey-round dummy; and $\mathrm{u}_{\mathrm{it}}$ is an iid error term.

The coefficient of interest is $\beta_{1}$, which estimates the effect of paternal departure on the outcome of interest. It may be that children's outcomes were affected even prior to the dissolution event, for instance due to conflict in the household, though we do not estimate this effect. Rather, if we observe negative (positive) effects on children, we can say that they are worse (better) off after the event than before it, whilst remaining silent on the extent to which their outcomes were affected pre-event.

The child fixed effects model eliminates any inherent, time-invariant, unobserved differences (or selection effects) between families that experience paternal departure and those that stay intact. The estimates are based on within-child comparisons across periods. In order to interpret these estimates as causal, there are two key identification assumptions. The first is that there are no unobserved time-varying factors affecting both paternal departure and children's outcomes. A second issue relates to reverse causation, in other words poor mental health of children may lead to the separation, rather than the other way round. It would be difficult to determine whether reverse causality is producing the results, though this issue is mitigated in our case as separations are measured prior to observing outcomes - we are estimating the effect of separation on later outcomes - thereby reducing the scope for simultaneity bias.

We modify equation (1) to allow for the effects of paternal departure to vary depending on when in childhood it occurred, and for departure in early childhood we also separate out shortand medium-term effects. 


$$
y_{i t}=\beta_{0}+\beta_{1} D_{i 1} \cdot 1[t=2 \mid 3]+\beta_{2} D_{i 1} \cdot 1[t=4 \mid 5]+\beta_{3} D_{i 2}+X_{i t}^{\prime} \beta_{2}+f_{i}+\delta_{t}+u_{i t}
$$

where $D_{i 1}=1$ if departure occurs in early childhood (between ages 3 and 7), 0 otherwise; $D_{i 2}$ $=1$ if departure occurs in mid-childhood (between ages 7 and 14), 0 otherwise. So $\beta_{1}$ estimates the (short-run) effect of paternal departure in early childhood on outcomes in mid-childhood (ages 5-7); $\beta_{2}$ is the (medium-run) effect of early childhood departure on outcomes in later childhood (ages 11-14), and $\beta_{3}$ is the (short-run) effect of mid-childhood departure (ages 7-14) on late childhood/adolescent outcomes (ages 11-14).

Dependent variables are standardised, so estimates can be interpreted as standard deviation changes in the dependent variable per unit change in the independent variable.

To deal with missing data, we include unit-non response attrition weights (Mostafa 2015). Item non-response on the main child outcomes is reduced by using a more relaxed criteria for calculating sub scales of the SDQ. As a minimum, two items out of five have to be available for each of the four SDQ subscales making up the respective externalising and internalising scales. The norm is a minimum of three items per subscale. As a robustness check, we ran all analyses using the conventional criteria, resulting in a slightly smaller sample size, and the results were qualitatively the same.

\section{Results}

\subsection{Descriptives}

Table 1 shows descriptive characteristics of the sample $(\mathrm{N}=6,245)$ at age 3 , and how it compares to the whole MCS sample (N=19,244). The study sample is more socioeconomically 
advantaged and less ethnically diverse. Moreover mothers are older, have lower levels of depression, and their children have fewer externalising and internalising problems.

[TABLE 1]

Table 2 shows the baseline characteristics of the sample, respectively for those families who remain intact and for those who go on to experience paternal departure during the period examined in this study. Families that subsequently experience paternal departure are less socioeconomically advantaged; mothers are more likely to be White, slightly younger, and report higher levels of depression. Their children display higher levels of mental health problems, both externalising $(\mathrm{p}<.001)$ and internalising $(\mathrm{p}<.05)$. This highlights that the event is not random, and underlines the importance of accounting for selection on unobservables. Regarding timing of paternal departure, 22\% took place between ages 3 and 5, 20\% between ages 5 and 7, 36\% between 7 and 11, and 22\% between 11 and 14 . Given varying lengths between waves, paternal departure is evenly distributed across the period covered.

[TABLE 2]

\subsection{Overall Effects}

Estimates from equation (1), based on unadjusted and adjusted OLS models and fixed effect (FE) models are shown in the top panel of Table 3. The coefficients are largest in the unadjusted OLS model, and smallest in the FE model. This illustrates the upward bias in OLS estimates, which reduces once unobserved time-invariant heterogeneity is accounted for.

In our preferred specification, the fixed effects model, there remains a significant effect of dissolution on both child externalising $(0.07 S D, \mathrm{p}<.01)$ and particularly child internalising $(0.13 S D, \mathrm{p}<.001)$ 


\section{[TABLE 3]}

\subsection{Heterogeneity}

The central panel of Table 3 shows effects by gender. In the adjusted OLS model, all estimates are significant for males and females, with the size of the estimates between 0.14 and 0.19 . Gender differences are not statistically significant. The fixed effect estimates show that paternal departure from the household adversely affects internalising symptoms of both males and females, and to a similar degree (0.12 SD, p<.001). For externalising symptoms, however, only males are negatively affected (0.09 SD, $\mathrm{p}<.01)$.

Maternal education is examined by high education (A-levels or higher) vs. low education (below A-levels). The lower panel of Table 3 shows that estimates for externalising and internalising problems are significant for both education levels. For internalising symptoms, OLS estimates are larger for children of mothers with low education. However, fixed effects estimates are reduced though remain significant, and interestingly, estimates by maternal education are not statistically different from each other.

\subsection{Timing and Duration}

We next analyse separately the short-term effects of departures in early and mid-childhood, and the medium-term effects of departures in early childhood. This provides insight into how the timing of and since the event matter, and permits an understanding of persistence/fade out in effects.

We note that early paternal departure refers to departure between ages 3 and 7 , and departure in mid-childhood refers to the 7-14 year old period. We distinguish between their short-run 
effects (i.e. effects in the period after the event) and for early departures, medium-run effects (i.e. effects in late childhood/adolescence).

Turning first to externalising outcomes, fixed effects estimates for the overall sample, displayed in the upper panel of Table 4, show no significant effect of early paternal departure on child externalising behaviour either in the short- or medium-term. However externalising outcomes are affected adversely in the short-term by departure that occurs in mid-childhood $(0.09 S D, \mathrm{p}<.01)$.

Parallel to findings for externalising problems, the fixed effect estimates show no significant effect of early paternal departure on children's internalising problems in the short- or mediumterm. However, paternal departure in mid-childhood results in an increase in internalising symptoms in the short-run $(0.16 S D, \mathrm{p}<.001)$.

[TABLE 4]

Given differential effects by gender observed in Table 3, we examine the extent to which timing of paternal departure matters for outcomes, separately by gender. Results are shown in the lower panel of Table 4. The detrimental effect of departure in mid-childhood on externalising behaviour is driven by males $(0.15 S D, \mathrm{p}<.01)$, whilst the estimate for females is not statistically significant. For internalising problems, there is no evidence that either gender are affected by paternal departure in early childhood in the short-term, and weak evidence that females are affected in the medium term $(0.11 S D, \mathrm{p}<.10)$. Paternal departure in mid-childhood is associated with increased internalising problems in late childhood for both males (0.19 SD, $\mathrm{p}<.001)$ and females $(0.14 S D, \mathrm{p}<.01)$. 


\subsection{Mechanisms}

We explore two potential channels through which paternal departure may affect children's outcomes - maternal mental health and household income. We study the impact of paternal departure on these outcomes directly, rather than including them as mediators and assessing directly the effect of paternal departure net of these effects. This is because first, these are just two of many potential mediators, and we see no reason to estimate the effect of departure net of these two only; and second, it is of considerable interest to assess directly how they are affected by departure.

Table 5 shows the effects of departure on maternal mental health and household income. Adjusted OLS models show moderate and significant associations with maternal mental health, indicating that paternal departure has a detrimental effect on maternal mental health both in the short-term following separation, and in the medium-term. Fixed effect estimates are lower: paternal departure in early childhood is not significantly associated with maternal depressive symptoms in mid-childhood, and later in childhood there is evidence of better maternal mental health following early paternal departure $(-0.11 S D, \mathrm{p}<0.05)$. Paternal departure in midchildhood affects negatively maternal mental health in late childhood $(0.12 S D, \mathrm{p}<.01)$.

Regarding household income, shown in the lower panel of Table 5, we find large negative correlations between departure and household income, which reduce but remain sizeable in the fixed effects model. The loss of household income following paternal departure is largest for departures that occur in mid-childhood.

[TABLE 5] 


\section{Discussion}

Using a large sample from the Millennium Cohort Study, a major ongoing longitudinal study following over 19,000 children in the UK born between 2000 and 2002, we examined the effects of paternal departure on child mental health through childhood to early adolescence. Child fixed effects were used to address the endogeneity of paternal departure. Heterogeneity of effects were examined by gender and maternal education. The effects of timing of departure, a largely understudied area, were considered. Finally, the paper examined the impact of departure on maternal mental health and household income.

In our sample of families, all intact at child age three, one fifth of them would go on to experience paternal departure by early adolescence. Comparing families who did and did not go on to experience departure highlighted important differences across the two even before the departure: families who subsequently split were more socioeconomically disadvantaged, had lower maternal age and higher levels of maternal depressive symptoms; their children were less well adjusted, particularly in terms of externalising problems. Child fixed effects are used to deal with this important issue of endogeneity, eliminating unobserved time-invariant factors affecting both children's mental health and paternal departure, and accounting for pre-existing differences in the two family types.

We find that paternal departure has a negative effect on child mental health, particularly on internalising symptoms. Striking gender differences emerge in examining effects by timing and duration. There are no short-term effects of departure in early childhood, and only weak evidence of medium-term effects, and for females only. Paternal departure in later childhood, on the other hand, is associated with an increase in internalising problems in both males and 
females. However only males exhibit higher levels of externalising behaviours. Maternal education is not found to be a protective factor.

Our results highlight the importance of accounting for unmeasured confounding: in adjusted OLS models the estimated effects are higher than the fixed effect estimates, thereby overstating the adverse effects on children's outcomes. Nonetheless, fixed effects models show that following paternal departure, children exhibit significant, albeit small, increases in both externalising and internalising symptoms. This reduction in bias when accounting for unmeasured confounding is echoed in previous studies (McLanahan et al. 2013). The larger effects on child internalising symptoms compared to externalising are also in line with previous studies (e.g. Amato and Anthony 2014, Strohschein 2005).

Compared to previous literature, the main difference in findings to emerge is that in our study, departure in mid-childhood matters more than in early childhood. Indeed, we find limited evidence that departure in early childhood affects children's mental health. Existing literature is mainly US focused, and one important difference is that our study in the UK, a context with very different social and welfare support systems. Another consideration is that our study is more recent, based on a contemporaneous sample of adolescents. Our sample of families experiencing dissolution is arguably quite different to those in earlier studies, due to the increase in divorce over time and reduction in associated stigma (Perelli-Harris et al. 2017), which may affect findings. Notwithstanding these differences, there are a number of reasons that may underlie discrepancies in findings. The first relates to the fact that our outcomes span ages $11-14$, whilst previous work considers ages to $11 / 12$. This is by no means an innocuous distinction: the transition to early adolescence is a critical developmental period, a key transitional time corresponding to major social and biological changes (World Bank 2006). It 
is a period during which stark changes emerge in mental health, particularly for females from 11 to 14 (Patalay and Fitzsimons 2018). Most previous studies do not consider this developmental period, which may affect findings. A second possible reason is our study focuses on a sample of intact families as at age 3. Therefore our study does not capture the effects of paternal departure in the first three years of life. Third, the lack of effects of early departure is consistent with our finding that over time, maternal mental health improves following early departure, and this may be a protective factor in children's outcomes (Fitzsimons et al. 2017).

Comparing our findings by maternal education to previous work, existing evidence is limited and mixed: on the one hand, in line with life course theory, Ryan et al (2015) find that the adverse effects of family structure changes are confined to children born to moderate- and highincome parents. On the other hand, in line with economic theory, Mandemakers and Kalmijn (2014) find that children whose mothers have high levels of education are better cushioned from the effects of father's departure. Our study finds no evidence of differential effects by maternal education, with both groups of children similarly adversely affected following departure in mid-childhood. This suggests there is a role for both life course theory and economic theory, and understanding how the mechanisms vary by family type is an important avenue for future research.

Another important finding regards maternal mental health. In examining some of the mechanisms that may contribute to children experiencing detrimental changes to their mental health following family dissolution we find that in the short run, up to four years after the break up, there is no significant change in maternal depressive symptoms following paternal departure in early childhood. However, in the longer term, four to eleven years after, early 
paternal departure is positively related to maternal mental health. Departure in later childhood is also associated with detrimental effects on maternal mental health, at least in the short term, whereas we do not yet have data that elucidate longer-term impact on mothers. It is possible that with time there will be a positive impact on maternal mental health as observed for those separating in early childhood, and as observed in previous studies (Lorenz et al. 2006; Andress and Brockel 2007). One potential contributing factor is re-partnership (Johnson and Wu 2002).

Regarding the impact of paternal departure on household income, we observe sizeable reductions, though the short-term income loss is larger for those families in which paternal departure occurred when children were older - most likely due to the well-known profile of lifecycle earnings, with earnings increasing with experience (e.g. Murphy and Welch 1990). The family may have to move home because of the decline in income, which could be disruptive to schooling and peer relationships. This may be especially detrimental for older children and early adolescents for whom peer relationships are increasingly important (Parker et al. 2006), which may play a role in the larger impact observed when paternal departure occurs later in childhood.

Despite the number of strengths of this study, there are some limitations. First, the data are observational, and our whilst our empirical strategy adjusts for time-invariant unobserved variables correlated with both exposure and outcomes, there may be residual confounding due to unobserved time varying factors affecting both. For instance, the onset of domestic violence, child abuse, parent substance use, or critical illness could be significant causal factors for both relationship breakdown and child mental health. So our models cannot establish causality, but offer an improvement upon many previous estimates in this literature. 
A second limitation concerns our selection criteria, including intact families at age 3 , when child mental health was first measured. We are therefore unable to shed light on the impact of paternal departure from infancy to age 3. There is compelling evidence on the importance of early family environment for children's trajectories (e.g. Kalil et al. 2012; Shonkoff and Phillips 2000), which this study cannot fully consider. It also limits the potential for direct comparisons with previous literature, much of which focuses on the 0-5 year period of early childhood.

A third limitation concerns the psychometric properties of the internalising measure at age 3 when the inter-item reliability was relatively low compared to later waves. This likely reflects the well-known difficulty in measuring internalising symptoms in young children, and a modified criteria of symptoms has been recommended for this age group (Luby et al. 2009). We are, however, limited to the existing SDQ scale, and although this may cause psychometric problems on one level, in our longitudinal study there is considerable gain in using the same measure across waves to track change.

A further limitation is that our study cannot shed light on the impact on child mental health of growing up in specific family structures, though this is the focus of previous work using the MCS (Mostafa et al. 2018). Further examination might include more longitudinal study of family structure, including mechanisms and protective factors that buffer the effect on children of family dissolution, remarriage, or living permanently in a single parent family.

Moreover, in terms of generalisability of our findings, our sample includes families that were more affluent, better educated and where mothers had better mental health functioning compared to the MCS sample as a whole. It is difficult to know how this might bias finding, 
though our estimates suggest that maternal education does not play a role in protecting children against adverse effects.

Finally, our study considers the effects after paternal departure from the household, and not the entire process through which it may have affected children. Children's symptoms and behaviour may be affected prior to departure (Arkes 2015) but this is not considered in this study. Moreover, the involvement of the father after he leaves the household is an important consideration. In our study, the majority continue to have some contact with their children (e.g. $89 \%$ at age 7), with many making a financial contribution to their maintenance (e.g. $60 \%$ at age 7). It is also possible that the parents have joint (or part) custody of the children, though we do not observe this. Nonetheless we acknowledge that such circumstances could buffer the negative effects of paternal departure, and this is an important avenue for further research.

From a policy perspective, this study highlights the negative consequences of paternal departure on children's outcomes, particularly manifest in adolescence. The evidence points to mid-childhood as a particularly sensitive period during which intervention may be needed; it also suggests that maternal mental health may be an important target area in terms of mitigating adverse consequences of the event on children's mental health. Furthermore, any policies to mitigate the adverse consequences should be targeted across the socioeconomic spectrum. 


\section{Acknowledgements}

The sixth sweep of the Millennium Cohort Study was core-funded by the Economic and Social Research Council (ESRC), and co-funded by the following consortium of government departments: Department for Education, Department of Health, Ministry of Justice, Home Office, Department for Transport, Department of Work and Pensions, Welsh Government and Department for Employment and Learning (Northern Ireland).

We are also grateful for funding from the Economic and Social Research Council via Grant ES/M001660/1.

The content is solely the responsibility of the authors and does not necessarily represent the official view of the funders.

\section{Data availability}

Data for the Millennium Cohort Study used in this paper is available from the UK Data Service. https://www.ukdataservice.ac.uk/

Declarations of interest: none 


\section{References}

Amato, P. R. (2001). Children of divorce in the 1990s: an update of the Amato and Keith (1991) meta-analysis. Journal of Family Psychology, 15(3), 355-370.

Amato, P. R. (2010). Research on divorce: Continuing trends and new developments. Journal of marriage and family, 72(3), 650-666.

Amato, P. R., \& Anthony, C. J. (2014). Estimating the effects of parental divorce and death with fixed effects models. Journal of Marriage and Family, 76(2), 370-386.

Amato, P. R., \& Keith, B. (1991). Parental divorce and the well-being of children: A metaanalysis. Psychological Bulletin, 110(1), 26-46.

Andress, H. J., \& Brockel, M. (2007). Income and life satisfaction after marital disruption in Germany. Journal of Marriage and Family, 69(2), 500-12.

Arkes, J. (2015). The temporal effects of divorces and separations on children's academic achievement and problem behavior. Journal of Divorce \& Remarriage, 56(1), 25-42.

Aughinbaugh, A., C. R. Pierret, and D. S. Rothstein. (2005). The impact of family structure transitions on youth achievement: evidence from the children of the NLSY79. Demography, 42(3), 447-68. 
Bandura, A. (1986). Social foundations of thought and action: A social cognitive theory. Englewood Cliffs, NJ, US: Prentice-Hall.

Ben-Shlomo, Y., Mishra, G., \& Kuh, D. (2014). Life course epidemiology. In W. Ahrens \& I. Pigeot (Eds). Handbook of Epidemiology. 2nd edn. New York, NY: Springer.

Ben-Shlomo, Y., \& Kuh, D. (2002). A life course approach to chronic disease epidemiology: conceptual models, empirical challenges and interdisciplinary perspectives. International Journal of Epidemiol, 31(2), 285-93.

Blekesaune, M. (2008). Partnership transitions and mental distress: Investigating temporal order. Journal of marriage and family, 70(4), 879-890.

Bowlby, J. (1969). Attachment and loss: Attachment (vol. 1). New York: Basic Books.

Brewer, M., \& Nandi, A. (2014). Partnership dissolution: how does it affect income, employment and well-being? (No. 2014-30). ISER Working Paper

Capaldi, D. M., \& Patterson, G. R. (1991). Relation of Parental Transitions to Boys' Adjustment Problems .1. A Linear-Hypothesis .2. Mothers at Risk for Transitions and Unskilled Parenting. Developmental Psychology, 27(3), 489-504.

Cavanagh, S. E., \& Huston, A.C. (2008). The Timing of Family Instability and Children's Social Development. Journal of Marriage and Family 70(5), 1258-70. 
Cavanagh, S. E., Crissey, S.R. \& Raley, R.K. (2008). Family structure history and adolescent romance. Journal of Marriage and Family, 70(3), 698-714.

Cherlin, A. J., Furstenberg, F. F., Chase-Lansdale, L., Kiernan, K. E., Robins, P. K., Morrison, D. R., \& Teitler, J. O. (1991). Longitudinal studies of effects of divorce on children in Great Britain and the United States. Science, 252(5011), 1386-1389.

Cherlin, A. J., Chase-Lansdale, P. L., \& McRae, C. (1998). Effects of parental divorce on mental health throughout the life course. American Sociological Review, 239-249.

Collins, W.A., \& Laursen, B. (1992). Conflict and relationships during adolescence. In C.U. Shantz \& W.W. Hartup (Eds.), Conflict in child and adolescent development (pp. 216-241). New York: Cambridge University Press.

D’Onofrio, B. M., Turkheimer, E., Emery, R. E., Heath, A. C., Madden, P. A., Slutske, W. S., \& Martin, N. G. (2006). A Genetically Informed Study of the Processes Underlying the Association Between Parental Marital Instability and Offspring Adjustment. Developmental Psychology, 42(3), 486-499.

D'onofrio, B. M., Turkheimer, E., Emery, R. E., Slutske, W. S., Heath, A. C., Madden, P. A., \& Martin, N. G. (2005). A genetically informed study of marital instability and its association with offspring psychopathology. Journal of Abnormal Psychology, 114(4), 570.

Doyle, A. B., \& Markiewicz, D. (1996). Parents' Interpersonal Relationships and Children's Friendships. In W. M. Bukowski, A. F. Newcomb, \& W. W. Hartup (Eds.), The 
Company They Keep: Friendship in Childhood and Adolescence. Cambridge: Cambridge University Press.

Emery R. E. (1999). Marriage, divorce, and children's adjustment (2nd ed.). Thousand Oaks, CA: Sage.

Fitzsimons, E. (2017). Millennium Cohort Study, Sixth Survey 2015-2016 User Guide (First Edition), London: Centre for Longitudinal Studies.

Fitzsimons, E., Goodman, A., Kelly, E., \& Smith, J. P. (2017). Poverty dynamics and parental mental health: Determinants of childhood mental health in the UK. Social Science \& Medicine, 175, 43-51.

Goodman, A., \& Goodman, R. (2009). Strengths and difficulties questionnaire as a dimensional measure of child mental health. Journal of the American Academy of Child \& Adolescent Psychiatry, 48(4), 400-403.

Goodman, A., Lamping, D. L., \& Ploubidis, G. B. (2010). When to use broader internalising and externalising subscales instead of the hypothesised five subscales on the Strengths and Difficulties Questionnaire (SDQ): data from British parents, teachers and children. Journal of abnormal child psychology, 38(8), 1179-1191.

Goodman, R. (1997). The Strengths and Difficulties Questionnaire: a research note. Journal of Child Psychology and Psychiatry, 38(5), 581-586. 
Green, H., McGinnity, A., Meltzer, H., Ford, T. \& Goodman, R., 2005. Mental health of children and young people in Great Britain, 2004. Basingstoke: Palgrave Macmillan.

Gruber, J. (2004). Is making divorce easier bad for children? The long-run implications of unilateral divorce. Journal of Labor Economics, 22(4), 799-833.

Johnson, D. R., \& Wu, J. (2002). An empirical test of crisis, social selection, and role explanations of the relationship between marital disruption and psychological distress: A pooled time-series analysis of four-wave panel data. Journal of Marriage and Family, 64(1), 211-24.

Joshi, H. E., \& Fitzsimons, E. (2016). The UK Millennium Cohort: the making of a multipurpose resource for social science and policy. Longitudinal and Life Course Studies, 7(4), 409-430.

Kalil, A., Ryan, R, \& Corey, M. (2012). Diverging destinies: maternal education and the developmental gradient in time with children. Demography, 49(4), 1361-83.

Kuh, D., Ben-Shlomo, Y., Lynch, J., Hallqvist, J., \& Power, C. (2003). Life course epidemiology. Journal of Epidemiology \& Community Health, 57(10), 778-783.

Lansford, J. E., Malone, P. S., Castellino, D. R., Dodge, K. A., Pettit, G. S., \& Bates, J. E. (2006). Trajectories of internalizing, externalizing, and grades for children who have and 
have not experienced their parents' divorce or separation. Journal of family Psychology, 20(2), 292-301.

Lorenz, F. O., Wickrama, K. A. S., Conger, R. D., \& Elder Jr, G. H. (2006). The short-term and decade-long effects of divorce on women's midlife health. Journal of Health and Social Behavior, 47(2), 111-125.

Luby, J. L., Si, X., Belden, A. C., Tandon, M., \& Spitznagel, E. (2009). Preschool depression: Homotypic continuity and course over 24 months. Archives of general psychiatry, 66(8), 897-905.

Mandemakers, J. J., \& Kalmijn, M. (2014). Do mother's and father's education condition the impact of parental divorce on child well-being? Social Science Research, 44, 187-199.

Markowitz, A. J., \& Ryan, R.M. (2016). Father Absence and Adolescent Depression and Delinquency: A Comparison of Siblings Approach. Journal of Marriage and Family, 78(5), 1300-1314.

Mathai, J., Anderson, P., \& Bourne, A. (2004). Comparing psychiatric diagnoses generated by the Strengths and Difficulties Questionnaire with diagnoses made by clinicians. Australian and New Zealand Journal of Psychiatry, 38(8), 639-643.

McLanahan, S., Tach, L., \& Schneider, D. (2013). The causal effects of father absence. Annual Review of Sociology, 39, 399-427. 
Mostafa, T (2015). Millennium Cohort Study: Technical report on response in sweep 5 (age 11). London: Centre for Longitudinal Studies, UCL Institute of Education.

Murphy, K., \&Welch, F. (1990). Empirical Age-Earnings Profiles. Journal of Labor Economics , 8(2), 202-229.

Office for National Statistics (2016). Statistical Bulletin on Families and Households in the $U K:$ 2016. Retrieved from https://www.ons.gov.uk/peoplepopulationandcommunity/birthsdeathsandmarriages/familie s/bulletins/familiesandhouseholds/2016

Mostafa, T., Gambaro, L \& Joshi, H. (2018). The Impact of Complex Family Structure on Child Well-being: Evidence From Siblings. Journal of Marriage and Family, 80(4), 902918.

Parker, J. G. , Rubin, K. H. , Erath , S. A. , Wojslawowicz , J. C. , \& Buskirk , A. A. (2006). Peer relationships, child development, and adjustment: A developmental psychopathology perspective . In D. Cicchetti \& D. J. Cohen (Eds.), Developmental psychopathology: Vol. 1: Theory and methods (2nd ed., pp. 96 - 161). New York: Wiley.

Patalay, P., \& Fitzsimons, E. (2018). Mental ill-health and wellbeing at age 14 - Initial findings from the Millennium Cohort Study Age 14 Survey. Centre for Longitudinal Studies, London. Available from:

http://www.cls.ioe.ac.uk/page.aspx? \&sitesectionid=2419\&sitesectiontitle=MCS + Age $+14+\mathrm{i}$ nitial+findings 
Perelli-Harris, B., Berrington, A., Sánchez Gassen, N., Galezewska, P., \& Holland, J. A. (2017). The rise in divorce and cohabitation: Is there a link?. Population and development review, 43(2), 303-329.

Pronzato, C., \& Aassve, A. (2013). Marital breakup and children's behavioural responses. Department of Economics and Statistics Cognetti de Martiis. Working Papers 201339, University of Turin.

Ryan, R. M., \& Claessens, A. (2013). Associations between family structure changes and children's behavior problems:The moderating effects of timing and marital birth. Developmental Psychology, 49, 1219-1231.

Ryan, R. M., Claessens, A., \& Markowitz, A. J. (2015). Associations between family structure change and child behavior problems: The moderating effect of family income. Child development, 86(1), 112-127.

Shonkoff, J. P., Garner, A. S., Committee on Psychosocial Aspects of Child and Family Health, \& Committee on Early Childhood, Adoption, and Dependent Care. (2011). The lifelong effects of early childhood adversity and toxic stress. Pediatrics, 129(1), E232E246.

Shonkoff, J.P. \& Phillips, D.A. (eds). (2000) From Neurons to Neighbourhoods: The science of early child development. Washington, DC:.National Academy Press. 
Strohschein, L. (2005). Parental divorce and child mental health trajectories. Journal of Marriage and Family, 67(5), 1286-1300.

Van de Walle, D. P. (2011). Lasting welfare effects of widowhood in a poor country.

Washington, DC: World Bank.

Weaver, J. M., \& Schofield, T. J. (2015). Mediation and moderation of divorce effects on children's behavior problems. Journal of Family Psychology, 29(1), 39-48.

Whiteside, M. F., \& Becker, B. J. (2000). Parental factors and the young child's postdivorce adjustment: a meta-analysis with implications for parenting arrangements. Journal of Family Psychology, 14(1), 5-26.

World Bank. (2006). World Development Report 2007: Development and the Next Generation. Washington D.C.: The International Bank for Reconstruction and Development / The World Bank 


\section{Tables}

Table 1 Characteristics of analysis sample and full MCS sample

\begin{tabular}{|c|c|c|c|c|c|}
\hline & & $\begin{array}{l}\text { Current sample } \\
(\mathrm{N}=6,245)\end{array}$ & & $\begin{array}{l}\text { ole MCS sample } \\
(\mathrm{N}=19,244)\end{array}$ & \\
\hline & $\mathrm{N}$ & $\begin{array}{l}\text { Percentage } \\
\text { or mean }\end{array}$ & $\mathrm{N}$ & $\begin{array}{l}\text { Percentage } \\
\text { or mean }\end{array}$ & $\begin{array}{l}\text { T-test difference } \\
\text { (p-value) }\end{array}$ \\
\hline $\begin{array}{l}\text { Household highest } \\
\text { educational level }\end{array}$ & 6,245 & & 19,204 & & \\
\hline NVQ1 & & $5.8 \%$ & & $8.3 \%$ & $\mathrm{p}<.001$ \\
\hline NVQ2 & & $25.8 \%$ & & $28.4 \%$ & $\mathrm{p}<.001$ \\
\hline NVQ3 & & $15.6 \%$ & & $14.3 \%$ & $\mathrm{p}<.01$ \\
\hline NVQ4 & & $39.8 \%$ & & $26.2 \%$ & $\mathrm{p}<.001$ \\
\hline NVQ5 & & $5.8 \%$ & & $3.7 \%$ & $\mathrm{p}<.001$ \\
\hline Overseas & & $1.7 \%$ & & $3.3 \%$ & $\mathrm{p}<.001$ \\
\hline None of these & & $5.4 \%$ & & $15.9 \%$ & $\mathrm{p}<.001$ \\
\hline $\begin{array}{l}\text { Household highest socioeconomic } \\
\text { class }\end{array}$ & 6,212 & & 18,144 & & \\
\hline SEC1 & & $25.7 \%$ & & $18.35 \%$ & $\mathrm{p}<.001$ \\
\hline SEC2 & & $14.3 \%$ & & $12.0 \%$ & $\mathrm{p}<.001$ \\
\hline SEC3 & & $13.7 \%$ & & $10.4 \%$ & $\mathrm{p}<.001$ \\
\hline SEC4 & & $10.1 \%$ & & $9.7 \%$ & $\mathrm{p}=.31$ \\
\hline SEC5 & & $36.2 .0 \%$ & & $49.6 \%$ & $\mathrm{p}<.001$ \\
\hline Household mean annual income ${ }^{a}$ & 6,232 & $£ 21,315$ & 19,120 & $£ 16,202$ & $\mathrm{p}<.001$ \\
\hline Maternal ethnicity (white) & 6,245 & $90.5 \%$ & 19,153 & $83.50 \%$ & $\mathrm{p}<.001$ \\
\hline Father departure & & & & & \\
\hline Age 9 months to 3 years & 0 & $0 \%$ & 16,376 & $9.4 \%$ & - \\
\hline Age 3 to 5 & 6,245 & $4.3 \%$ & 15,244 & $7.0 \%$ & $\mathrm{p}<.001$ \\
\hline Age 5 to 7 & 6,245 & $3.9 \%$ & 14,267 & $6.2 \%$ & $\mathrm{p}<.001$ \\
\hline Age 7 to 11 & 6,245 & $7.0 \%$ & 12,922 & $8.9 \%$ & $\mathrm{p}<.001$ \\
\hline Age 11 to 14 & 6,245 & $4.0 \%$ & 11,357 & $7.0 \%$ & $\mathrm{p}<.001$ \\
\hline Age 9 months to 14 years & 6,245 & $19.1 \%$ & 12,047 & $37.1 \%$ & $\mathrm{p}<.001$ \\
\hline Child sex (female) & 6,245 & $50.9 \%$ & 19,244 & $48.6 \%$ & $\mathrm{p}<.001$ \\
\hline Maternal age at birth & 6,245 & $30.3(5.07)$ & 19,234 & $28.31(6.01)$ & $\mathrm{p}<.001$ \\
\hline Maternal depression & 5,603 & $2.81(3.22)$ & 13,590 & $3.28(3.76)$ & $\mathrm{p}<.001$ \\
\hline Child externalising & 6,245 & $6.10(3.52)$ & 14,778 & $6.77(3.84)$ & $\mathrm{p}<.001$ \\
\hline Child internalising & 6,245 & $2.62(2.38)$ & 14,781 & $2.97(2.58)$ & $\mathrm{p}<.001$ \\
\hline
\end{tabular}

Notes:

Figures are for baseline at child age 3 if not otherwise indicated.

$\mathrm{NVQ}=$ National Vocational Qualifications (higher levels signify higher educational achievement and training)

SEC1 = Higher managerial, administrative and professional, SEC2 = Small employers and self-employed, SEC3= Small employers and selfemployed, SEC4= Lower supervisory and technical, SEC5= Semi-routine and routine.

Standard deviations are shown in parentheses.

${ }^{a}$ OECD equalised annual income. 
Table 2 Characteristics of families: intact families versus families with paternal departure

\begin{tabular}{|c|c|c|c|}
\hline & $\begin{array}{l}\text { Intact families } \\
(\mathrm{N}=5,048)\end{array}$ & $\begin{array}{l}\text { Paternal departure } \\
\text { families } \\
(\mathrm{N}=1,197)\end{array}$ & $\begin{array}{l}\text { T-test } \\
\text { difference } \\
\text { (p-value) }\end{array}$ \\
\hline \multicolumn{4}{|l|}{ Household highest educational level } \\
\hline NVQ1 & $5.2 \%$ & $8.7 \%$ & $\mathrm{p}<.001$ \\
\hline NVQ2 & $24.8 \%$ & $30.3 \%$ & $\mathrm{p}<.001$ \\
\hline NVQ3 & $15.4 \%$ & $16.4 \%$ & $\mathrm{p}=.42$ \\
\hline NVQ4 & $41.7 \%$ & $31.7 \%$ & $\mathrm{p}<.001$ \\
\hline NVQ5 & $6.3 \%$ & $3.7 \%$ & $\mathrm{p}<.001$ \\
\hline Overseas qualifications & $1.8 \%$ & $1.3 \%$ & $\mathrm{p}=.26$ \\
\hline None of these & $4.8 \%$ & $7.9 \%$ & $\mathrm{p}<.001$ \\
\hline \multicolumn{4}{|l|}{ Household highest socioeconomic class } \\
\hline SEC1 & $27.7 \%$ & $17.5 \%$ & $\mathrm{p}<.001$ \\
\hline SEC2 & $14.9 \%$ & $12.0 \%$ & $\mathrm{p}<.01$ \\
\hline SEC3 & $14.0 \%$ & $12.4 \%$ & $\mathrm{p}=.15$ \\
\hline SEC4 & $9.8 \%$ & $11.4 \%$ & $\mathrm{p}=.11$ \\
\hline SEC5 & $33.7 \%$ & $46.8 \%$ & $\mathrm{p}<.001$ \\
\hline Household annual income ${ }^{b}$ & $£ 22,069(12,041)$ & $£ 18,139(10,053)$ & $\mathrm{p}<.001$ \\
\hline Maternal ethnicity (white) & $89.7 \%$ & $93.9 \%$ & $\mathrm{p}<.001$ \\
\hline Child sex (female) & $50.5 \%$ & $52.5 \%$ & $\mathrm{p}=.23$ \\
\hline Maternal age at birth & $30.6(4.94)$ & $28.8(5.35)$ & $\mathrm{p}<.001$ \\
\hline Maternal depression age 3 & $2.63(3.07)$ & $3.56(3.72)$ & $\mathrm{p}<.001$ \\
\hline Child externalising behaviour age 3 & $5.98(3.46)$ & $6.64(3.72)$ & $\mathrm{p}<.001$ \\
\hline Child internalising behaviour age 3 & $2.60(2.39)$ & $2.75(2.34)$ & $\mathrm{p}<.05$ \\
\hline
\end{tabular}

Notes:

Figures are for baseline at child age 3 if not otherwise indicated.

SEC1 = Higher managerial, administrative and professional, SEC2 = Small employers and self-employed, SEC3= Small employers and selfemployed, SEC4= Lower supervisory and technical, SEC5= Semi-routine and routine.

Standard deviations are shown in parentheses.

${ }^{a}$ OECD equalised annual income. 
Table 3 Paternal departure and child externalising and internalising

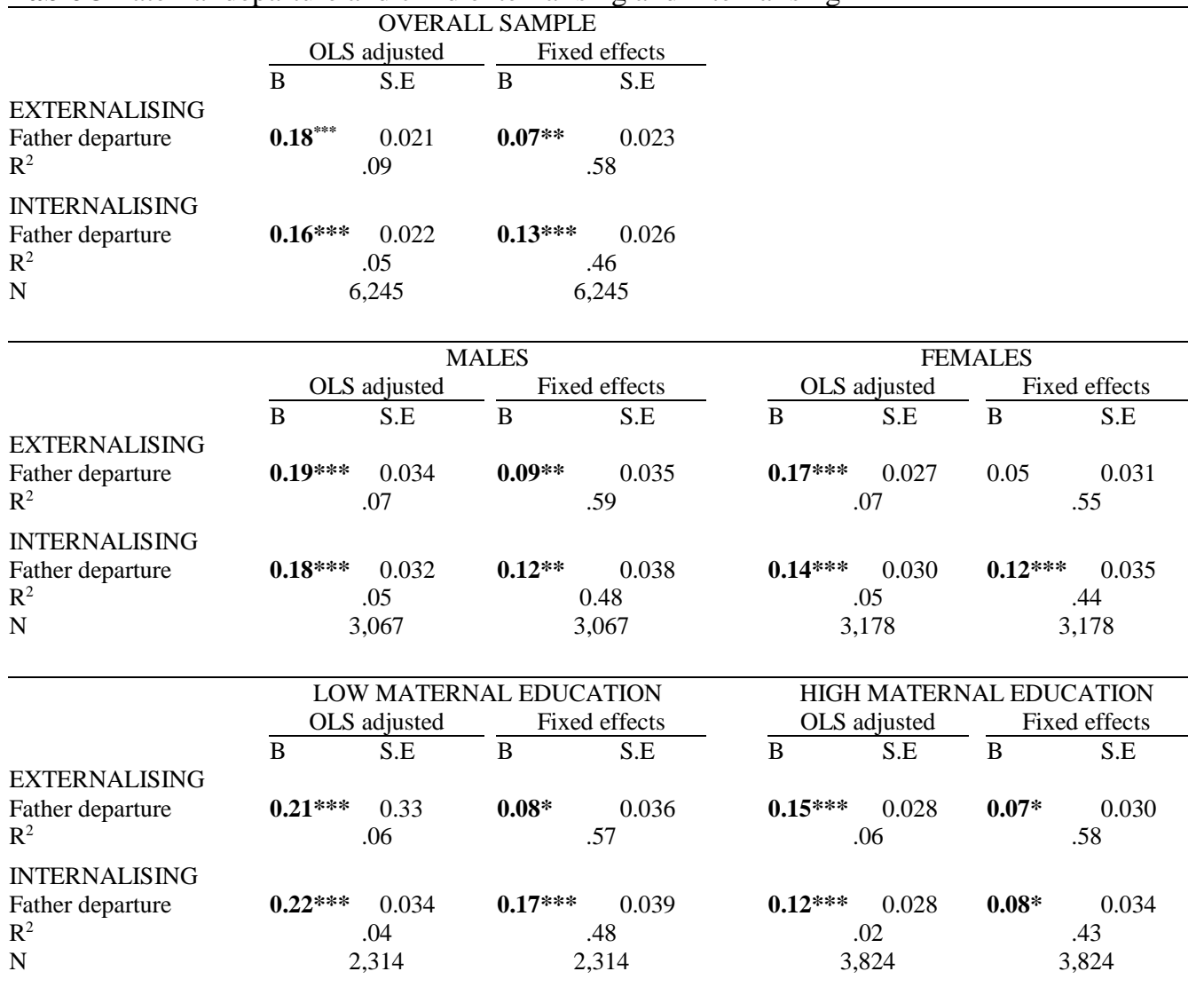

Notes:

Adjusted OLS model adjusted for: child gender, child age, child age squared, maternal age at birth, ethnicity, maternal educational level, household social economic class, household income, UK country, survey wave. FE model adjusted for child age and child age squared.

Low education: NVQ level 1 or 2, or no qualifications. High education: NVQ 3 to 5.

Dependent variables are standardized.

Standard errors are robust.

${ }^{\dagger} \mathrm{p}<.10, * \mathrm{p}<.05, * * \mathrm{p}<.01, * * * \mathrm{p}<.001$ 
Table 4 Timing of paternal departure and child externalising and internalising

\begin{tabular}{|c|c|c|c|c|c|c|c|c|}
\hline & \multicolumn{4}{|c|}{ OVERALL SAMPLE } & & & & \\
\hline & \multicolumn{2}{|c|}{ OLS adjusted } & \multicolumn{2}{|c|}{ Fixed effects } & & & & \\
\hline & $\bar{B}$ & S.E & B & S.E & & & & \\
\hline \multicolumn{9}{|l|}{ EXTERNALISING } \\
\hline \multicolumn{9}{|l|}{ Short-term effects of: } \\
\hline Departure in early childhood a & $0.18 * * * *$ & 0.040 & 0.02 & 0.041 & & & & \\
\hline Departure in mid-childhood ${ }^{\mathrm{b}}$ & $0.17 * * *$ & 0.035 & $0.09 * *$ & 0.029 & & & & \\
\hline \multicolumn{9}{|l|}{ Medium-term effects of: } \\
\hline Departure in early childhood ${ }^{c}$ & $0.21 * * *$ & 0.035 & 0.05 & 0.039 & & & & \\
\hline & \multicolumn{2}{|c|}{.09} & \multicolumn{2}{|c|}{.58} & & & & \\
\hline \multicolumn{9}{|l|}{ INTERNALISING } \\
\hline \multicolumn{9}{|l|}{ Short-term effects of: } \\
\hline Departure in early childhood a & $0.12 * *$ & 0.041 & 0.05 & 0.047 & & & & \\
\hline Departure in mid-childhood ${ }^{\mathrm{b}}$ & $0.22 * * *$ & 0.035 & $0.16 * * *$ & 0.032 & & & & \\
\hline \multicolumn{9}{|l|}{ Medium-term effects of: } \\
\hline Departure in early childhood ${ }^{c}$ & $0.14 * * *$ & 0.035 & 0.07 & 0.044 & & & & \\
\hline $\mathrm{R}^{2}$ & \multicolumn{2}{|c|}{.05} & \multicolumn{2}{|c|}{.46} & & & & \\
\hline \multirow[t]{4}{*}{$\mathrm{N}$} & \multicolumn{2}{|c|}{6,245} & \multicolumn{2}{|c|}{6,245} & & & & \\
\hline & \multicolumn{4}{|c|}{ MALES } & \multicolumn{4}{|c|}{ FEMALES } \\
\hline & \multicolumn{2}{|c|}{ OLS adjusted } & \multicolumn{2}{|c|}{ Fixed effects } & OLS & djusted & \multicolumn{2}{|c|}{ Fixed effects } \\
\hline & $\mathrm{B}$ & S.E & $\mathrm{B}$ & S.E & $\mathrm{B}$ & S.E & $\mathrm{B}$ & S.E \\
\hline \multicolumn{9}{|l|}{ EXTERNALISING } \\
\hline \multicolumn{9}{|l|}{ Short-term effects of: } \\
\hline Departure in early childhood ${ }^{a}$ & 0.03 & 0.063 & -0.02 & 0.063 & $0.17 * *$ & 0.047 & 0.07 & 0.055 \\
\hline Departure in mid-childhood ${ }^{\mathrm{b}}$ & $0.18 * *$ & 0.052 & $0.15 * *$ & 0.043 & 0.01 & 0.043 & 0.04 & 0.038 \\
\hline \multicolumn{9}{|l|}{ Medium-term effects of: } \\
\hline Departure in early childhood ${ }^{c}$ & $0.16 * *$ & 0.053 & 0.06 & 0.058 & $0.15 * *$ & 0.041 & 0.05 & 0.053 \\
\hline $\mathrm{R}^{2}$ & \multicolumn{2}{|r|}{.12} & \multicolumn{2}{|c|}{.59} & & 12 & & .55 \\
\hline INTERNALISING & & & & & & & & \\
\hline Short-term effects of: & & & & & & & & \\
\hline Departure in early childhood a & 0.06 & 0.062 & 0.03 & 0.071 & -0.01 & 0.051 & 0.08 & 0.061 \\
\hline Departure in mid-childhood ${ }^{b}$ & $0.15 * *$ & 0.048 & $0.19 * * *$ & 0.046 & 0.11* & 0.047 & $0.14 * *$ & 0.044 \\
\hline Medium-term effects of: & & & & & & & & \\
\hline Departure in early childhood ${ }^{c}$ & $0.07 *$ & 0.048 & 0.01 & 0.063 & 0.07 & 0.045 & $0.11^{\dagger}$ & 0.061 \\
\hline $\mathrm{R}^{2}$ & & .13 & & & & 12 & & .44 \\
\hline $\mathrm{N}$ & &, 067 & & & & 178 & & 3,178 \\
\hline $\begin{array}{l}\text { Notes: } \\
\text { a Father departure age } 3 \text { to } 5 \text { (age } \\
\text { b Father departure age } 7 \text { to } 11 \text { (ag } \\
\text { c Father departure age } 3 \text { to } 7 \text { on } ~ \\
\text { Adjusted OLS model adjusted fo } \\
\text { educational level, household soci } \\
\text { age and child age squared. } \\
\text { Low education: NVQ level } 1 \text { or } 2 \\
\text { Dependent variables are standard } \\
\text { Standard errors are robust. } \\
{ }^{\dagger} \mathrm{p}<.10,{ }^{*} \mathrm{p}<.05, * * \mathrm{p}<.01, * * * \mathrm{p}<.\end{array}$ & $\begin{array}{l}5 \text { to } 7 \text { ) or } \\
\text { il to } 14 \\
\text { hild outco } \\
: \text { child ge } \\
\text { al econom } \\
\text { or no qu } \\
\text { ized. }\end{array}$ & $\begin{array}{l}\text { child out } \\
\text { ) on child } \\
\text { mes age } 1 \\
\text { ader, child } \\
\text { ic class, h } \\
\text { alification }\end{array}$ & $\begin{array}{l}\text { nes age } 5 \text { a } \\
\text { tcomes age } \\
\text { o } 14 \text {. } \\
\text { e, child ag } \\
\text { ehold inco } \\
\text { tigh educa }\end{array}$ & $\begin{array}{l}1 \text { and } 14 \\
\text { squared, } \\
\text { e, UK co } \\
\text { n: NVQ }\end{array}$ & $\begin{array}{l}\text { 14). } \\
\text { nal age at } \\
\text {, survey v } \\
5 .\end{array}$ & $\begin{array}{l}\text { irth, eth } \\
\text { ve. FE n }\end{array}$ & $\begin{array}{l}\text { ity, mate } \\
\text { lel adjus }\end{array}$ & $\begin{array}{l}\text { rnal } \\
\text { ted for child }\end{array}$ \\
\hline
\end{tabular}


$\underline{\text { Table } 5 \text { Timing of paternal departure and maternal mental ill-health and household income }}$

MATERNAL MENTAL HEALTH

Short-term effects of:

Departure in early childhood ${ }^{\mathrm{a}}$
Departure in mid-childhood ${ }^{\mathrm{b}}$ Medium-term effects of:

Departure in early childhood ${ }^{\mathrm{c}}$

Observations

$\mathrm{N}$

\section{HOUSEHOLD INCOME}

Short-term effects of:

Departure in early childhood ${ }^{\mathrm{a}}$

Departure in mid-childhood ${ }^{\mathrm{b}}$ Medium-term effects of:

Departure in early childhood ${ }^{\mathrm{c}}$

Observations

$\mathrm{N}$

Notes

${ }^{\text {a }}$ Father departure age 3 to 5 (age 5 to 7) on child outcomes age 5 and 7 (age 7).

${ }^{\mathrm{b}}$ Father departure age 7 to 11 (age 11 to 14 ) on child outcomes age 11 and 14 (age 14).

${ }^{\mathrm{c}}$ Father departure age 3 to 7 on child outcomes age 11 to 14 .

Adjusted OLS model adjusted for: child gender, child age, child age squared, maternal age at birth, ethnicity, maternal educational level, household social economic class, household income, UK country, survey wave. FE model adjusted for child age and child age squared. Dependent variables are standardized.

Standard errors are robust.

${ }^{\dagger} \mathrm{p}<.10, * \mathrm{p}<.05, * * \mathrm{p}<.01, * * * \mathrm{p}<.001$

$\frac{\text { OLS adjusted }}{\text { B }} \frac{}{\text { S.E }} \frac{\text { Fixed effects }}{\text { B }}$

\begin{tabular}{crrr}
$\mathbf{0 . 3 8} * * *$ & 0.051 & 0.06 & 0.054 \\
$\mathbf{0 . 3 0} * * *$ & 0.039 & $\mathbf{0 . 1 2} * *$ & 0.035 \\
& & & \\
$\mathbf{0 . 2 3}^{*} * * *$ & 0.040 & $\mathbf{- 0 . 1 1}^{*}$ & 0.049 \\
\multicolumn{2}{c}{.05} & & .53 \\
30,211 & & 30,211 \\
6,042 & & 6,042
\end{tabular}

\begin{tabular}{|c|c|c|c|}
\hline$-0.60 * * *$ & 0.025 & $-0.39 * * *$ & 0.029 \\
\hline$-0.90 * * *$ & 0.020 & $-0.65 * * *$ & 0.020 \\
\hline$-0.79 * * *$ & 0.022 & $-0.48 * * *$ & 0.026 \\
\hline \multicolumn{2}{|c|}{.42} & \multicolumn{2}{|c|}{.67} \\
\hline \multicolumn{2}{|c|}{31,023} & \multicolumn{2}{|c|}{31,023} \\
\hline \multicolumn{2}{|c|}{6,204} & \multicolumn{2}{|c|}{6,204} \\
\hline
\end{tabular}

